\title{
Trends in health workers' compliance with outpatient malaria case-management guidelines across malaria epidemiological zones in Kenya, 2010-2016
}

Beatrice Amboko ${ }^{1 *} \mathbb{0}$, Kasia Stepniewska ${ }^{2,3}$, Peter M. Macharia' ${ }^{1}$, Beatrice Machini ${ }^{4}$, Philip Bejon ${ }^{1,3}$, Robert W. Snow ${ }^{1,3}$ and Dejan Zurovac ${ }^{1,3}$

\begin{abstract}
Background: Health workers' compliance with outpatient malaria case-management guidelines has been improving, specifically regarding the universal testing of suspected cases and the use of artemisinin-based combination therapy (ACT) only for positive results (i.e.,'test and treat'). Whether the improvements in compliance with 'test and treat' guidelines are consistent across different malaria endemicity areas has not been examined.

Methods: Data from 11 national, cross-sectional, outpatient malaria case-management surveys undertaken in Kenya from 2010 to 2016 were analysed. Four primary indicators (i.e.,' 'test and treat') and eight secondary indicators of artemether-lumefantrine (AL) dosing, dispensing, and counselling were measured. Mixed logistic regression models were used to analyse the annual trends in compliance with the indicators across the different malaria endemicity areas (i.e., from highest to lowest risk being lake endemic, coast endemic, highland epidemic, semi-arid seasonal transmission, and low risk).

Results: Compliance with all four 'test and treat' indicators significantly increased in the area with the highest malaria risk (i.e., lake endemic) as follows: testing of febrile patients ( $\mathrm{OR}=1.71$ annually; $95 \% \mathrm{Cl}=1.51-1.93)$, AL treatment for test-positive patients ( $\mathrm{OR}=1.56 ; 95 \% \mathrm{Cl}=1.26-1.92)$, no anti-malarial for test-negative patients $(\mathrm{OR}=2.04 ; 95 \%$ $\mathrm{Cl}=1.65-2.54)$, and composite 'test and treat' compliance $(\mathrm{OR}=1.80 ; 95 \% \mathrm{Cl}=1.61-2.01)$. In the low risk areas, only compliance with test-negative results significantly increased $(\mathrm{OR}=2.27 ; 95 \% \mathrm{Cl}=1.61-3.19)$ while testing of febrile patients showed declining trends $(\mathrm{OR}=0.89 ; 95 \% \mathrm{Cl}=0.79-1.01)$. Administration of the first AL dose at the facility significantly increased in the areas of lake endemic $(\mathrm{OR}=2.33 ; 95 \% \mathrm{Cl}=1.76-3.10)$, coast endemic $(\mathrm{OR}=5.02 ; 95 \%$ $\mathrm{Cl}=2.77-9.09)$ and semi-arid seasonal transmission $(\mathrm{OR}=1.44 ; 95 \% \mathrm{Cl}=1.02-2.04)$. In areas of the lowest risk of transmission and highland epidemic zone, none of the AL dosing, dispensing, and counselling tasks significantly changed over time.
\end{abstract}

Conclusions: There is variability in health workers' compliance with outpatient malaria case-management guidelines across different malaria-risk areas in Kenya. Major improvements in areas of the highest risk have not been seen in low-risk areas. Interventions to improve practices should be targeted geographically.

*Correspondence: BAmboko@kemri-wellcome.org

${ }^{1}$ KEMRI-Wellcome Trust Research Programme, P.O. Box 43640-00100, Nairobi, Kenya

Full list of author information is available at the end of the article

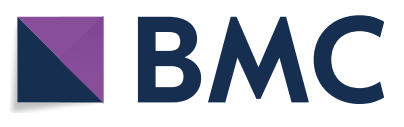

(c) The Author(s) 2020. This article is licensed under a Creative Commons Attribution 4.0 International License, which permits use, sharing, adaptation, distribution and reproduction in any medium or format, as long as you give appropriate credit to the original author(s) and the source, provide a link to the Creative Commons licence, and indicate if changes were made. The images or other third party material in this article are included in the article's Creative Commons licence, unless indicated otherwise in a credit line to the material. If material is not included in the article's Creative Commons licence and your intended use is not permitted by statutory regulation or exceeds the permitted use, you will need to obtain permission directly from the copyright holder. To view a copy of this licence, visit http://creativeco mmons.org/licenses/by/4.0/. The Creative Commons Public Domain Dedication waiver (http://creativecommons.org/publicdomain/ zero/1.0/) applies to the data made available in this article, unless otherwise stated in a credit line to the data. 
Keywords: Malaria, Outpatient, Case-management, Malaria endemicity, Compliance, 'Test and treat', Kenya

\section{Background}

Malaria continues to pose a huge public health threat in Africa [1]. In 2018, the WHO estimated 228 million cases and 405,000 deaths due to malaria, with over $90 \%$ of the deaths occurring in Africa [2]. Effective case-management remains the bedrock of malaria control [3]. In 2010, the globally recommended practice was universal testing of all suspected malaria patients and treatment of only test-positive patients with artemisinin-based combination therapy (ACT). This standard is referred to as 'test and treat' policy [4]. Effective supply chains must ensure universal and continuous availability of malaria testing and $\mathrm{ACT}$ as a basic pre-requisite for the policy implementation at health facilities. However, the effectiveness of test-based management also depends on how well healthcare workers comply with malaria case-management guidelines when attending to suspected cases [5-9].

Since 2010, despite the increased availability of parasitological diagnostics and ACT, studies among outpatients have reported sub-optimal health workers' compliance with 'test and treat' malaria guidelines [922], including poor ACT dosing, dispensing and counselling practices $[10,17,22-24]$. These studies have been undertaken on a small, often single facility sample $[16,19,21,23,25-27]$; at a single point of time $[9,10$, $13,15-17,22,23,28]$; have measured only a few indicators (e.g., treatment practices only) $[14,20,25,29$, 30 ], or were limited to specific outpatient groups (e.g., children only) [12, 13, 19, 26, 28, 29, 31]. Several larger outpatient studies have suggested improvements in specific compliance indicators, such as testing of febrile patients or compliance with test-negative results [17, $22,32,33]$. It has also been suggested that the malaria transmission setting influences 'test and treat' practices [34, 35], but trends in compliance indicators have not been widely explored in relation to malaria transmission intensities [19, 22].

In Kenya, health facility malaria case-management surveys have been regularly undertaken 11 times between 2010 and 2016 to monitor national progress in compliance with outpatient malaria guidelines. These surveys have shown improvements in a series of indicators since the launch of the 'test and treat' policy and surveys in 2010 [18, 21]. What have not been described previously are the temporal patterns of casemanagement compliance by health workers working in different malaria epidemiological settings. The present analysis aims to examine 2010-2016 compliance trends within and between malaria epidemiological zones in Kenya to identify sub-national deficiencies in compliance with guidelines.

\section{Methods \\ Stratification of malaria epidemiological zones}

Kenya supports a range of malaria transmission conditions within its national borders [36]. Despite major shifts in the intensity of malaria transmission over the last 25 years [36], the Kenya National Malaria Control Programme's (NMCP) malaria stratification of the country considers five malaria epidemiological zones based on ecological differences and historical prevalence of malaria [37-40]. The five zones are as follows: (1) lake endemic: high transmission areas around Lake Victoria in western Kenya with stable malaria transmission all year round, described here as 'high risk'; (2) coast endemic: low to moderate transmission areas along the Indian Ocean coast described here as 'moderate risk'; (3) highland epidemic: these are areas of the western highlands with unstable, year-to-year variation in transmission; (4) semi-arid, seasonal transmission: arid and semi-arid areas of northern, eastern and south eastern Kenya with acute seasonal and low transmission; and, (5) low risk: areas of central highlands including Nairobi with low transmission [39, 40]. Plasmodium falciparum parasite prevalence standardized to ages 2-10 years $\left(P f \mathrm{PR}_{2-10}\right)$, a measure of malaria transmission, ranged between 0.3 and $28 \%$ in 2010, and 0.3 and $21 \%$ in 2015 across the five epidemiological zones [36] (Fig. 1). The annual trends in $P f \mathrm{PR}_{2-10}$ across the five epidemiological zones between 2010 and 2015 are presented in Fig. 2. The population at risk ranged between 3 and 12 million people across the five zones in 2009 (Fig. 1) [39].

\section{Malaria case-management standards}

Figure $3 \mathrm{a}$ and $\mathrm{b}$ are the 2010 outpatient malaria casemanagement algorithms that apply to all epidemiological zones, age groups and levels of care in Kenya. With respect to malaria diagnosis, the 2010 policy recommends universal parasitological testing of all patients with fever across all areas of malaria transmission with either malaria microscopy or rapid diagnostic tests (RDTs), and subsequent anti-malarial treatment for test-positive patients only [37]. The recommended first-line treatment for uncomplicated malaria is artemether-lumefantrine (AL) since 2006 $[44,45]$. Finally, recognizing the greater complexity of AL dosing and administration compared to the 


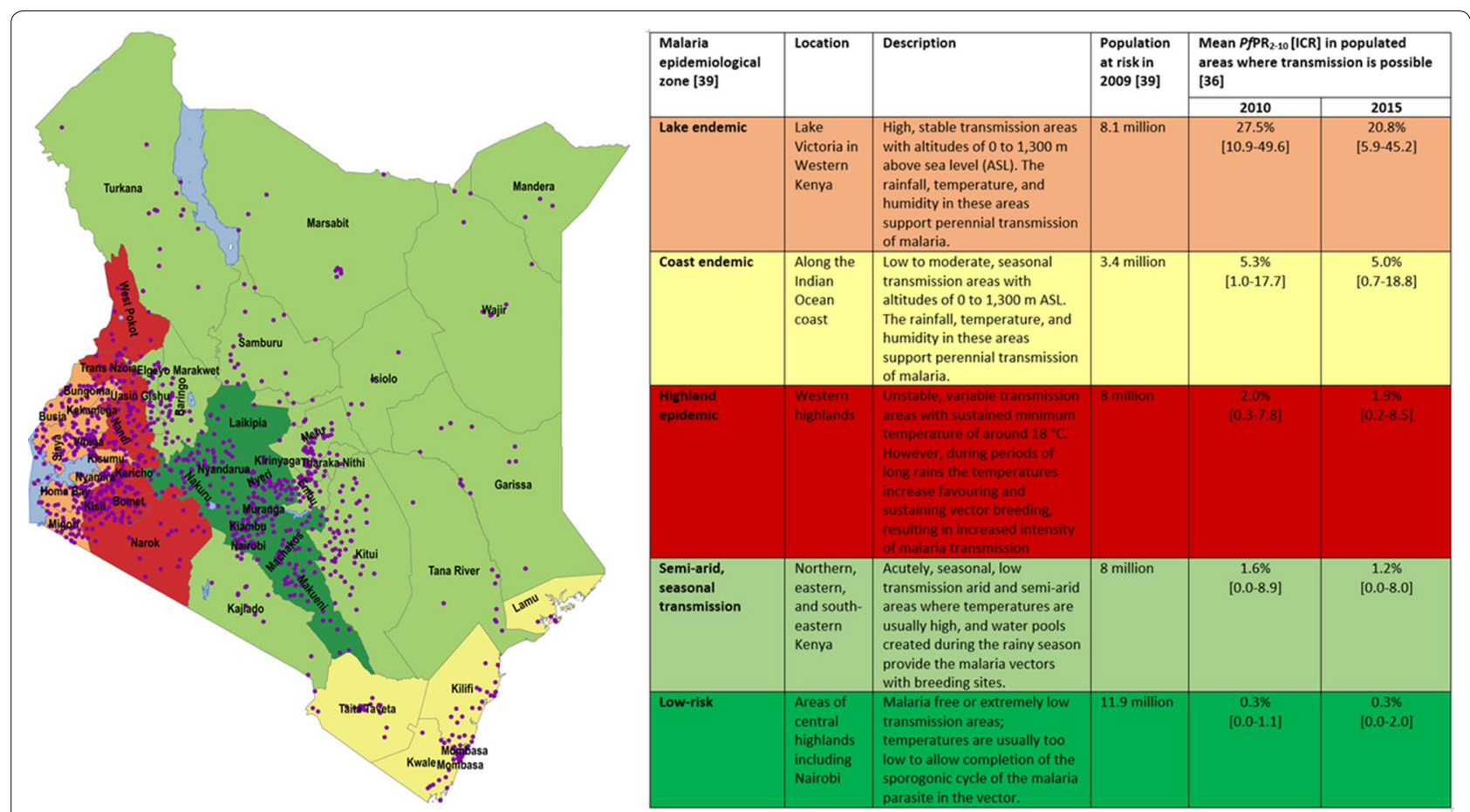

Fig. 1 Malaria endemicity zones in Kenya and the sampled facilities as purple dots

\begin{abstract}
(See figure on next page.)
Fig. 2 The annual mean PfPR 2 -10 by malaria epidemiological zones and the test-based policy implementation activities, 2010-2016. To characterize the annual malaria parasite prevalence in the five malaria epidemiological zones of Kenya (lake endemic, coast endemic, highland epidemic, semi-arid seasonal transmission and low risk) we used previously published modelling work [36]. In brief, 5020 Plasmodium falciparum parasite prevalence (PfPR) surveys at 3701 communities undertaken in Kenya between 1980 and 2015 were assembled. A spatio-temporal geostatistical model was fitted to predict the annual mean malaria risk and corresponding 2.5-97.5\% interquartile credibility range (ICR) for children aged 2-10 years $\left(P A P R_{2-10}\right)$ at $1 \times 1 \mathrm{~km}$ spatial resolution. The model accounted for unmeasured spatio-temporal risk factors (structured random effects) and unexplained variation within communities (unstructured random effects) while standardizing for age. The annual average PfPR $2-10$ and ICR by zone from 2010 to 2015 was then computed for populated areas where malaria transmission is possible. Areas that do not support malaria transmission were defined based on a temperature suitability index (TSI) (TSI zero areas) constructed using land surface temperatures, the average survival of Anopheles mosquitoes and the length of sporogony that must be completed within the lifetime of one Anopheline generation [41]. Populated areas were defined as locations with at least 1 person per $\mathrm{km}^{2}$ based on population density maps [42] available at Worldpop data geoportal [43]. The annual mean PfPR $2-10$ in populated areas able to support transmission in each of the five MoH epidemiological zones (Fig. 1) were extracted and mapped using ArcMap 10.5 (ESRI Inc., Redlands, CA, USA) and shown for each year 2010-2015 in Fig. 2, against the major milestones of the policy change and implementation
\end{abstract}

previous single-dose monotherapy, the 2010 guidelines for health workers emphasized AL dosing, dispensing and counselling tasks that should be performed for all patients treated with AL (Fig. 3b) [37]. Since the launch of new case-management policy in 2010, its implementation has been countrywide, across all epidemiological zones, achieved through routine programmatic activities such as strengthening of the supply chain for 'test and treat' commodities, dissemination of revised guidelines and job aids, a series of in-service case-management training for health workers and strengthening of the supportive supervision and quality assurance for malaria microscopy.

Other contextual factors during this period include central level stock-outs of AL and RDTs in 2013 and 2014 due to a fire at the Kenya Medical Supplies Agency (KEMSA) stores and levy tax that delayed the delivery of commodities. Moreover, in 2015, MalariaCare, a USAID partnership, began working in the lake endemic zone to improve the quality of diagnosis and treatment of malaria and other febrile illnesses [46]. The implemented activities included case-management and laboratory training, on-site supervision, and mentoring [known as 'outreach 

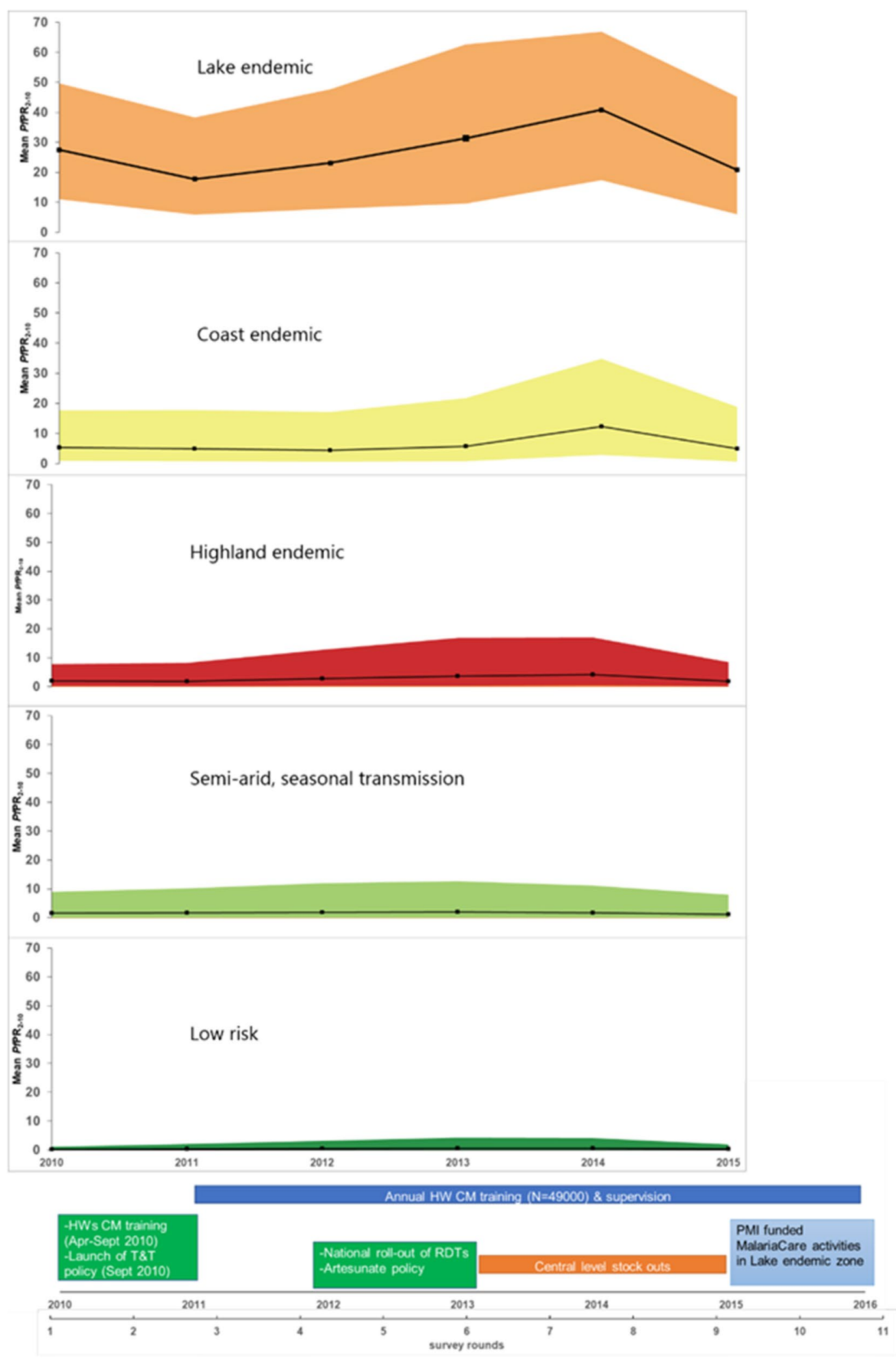


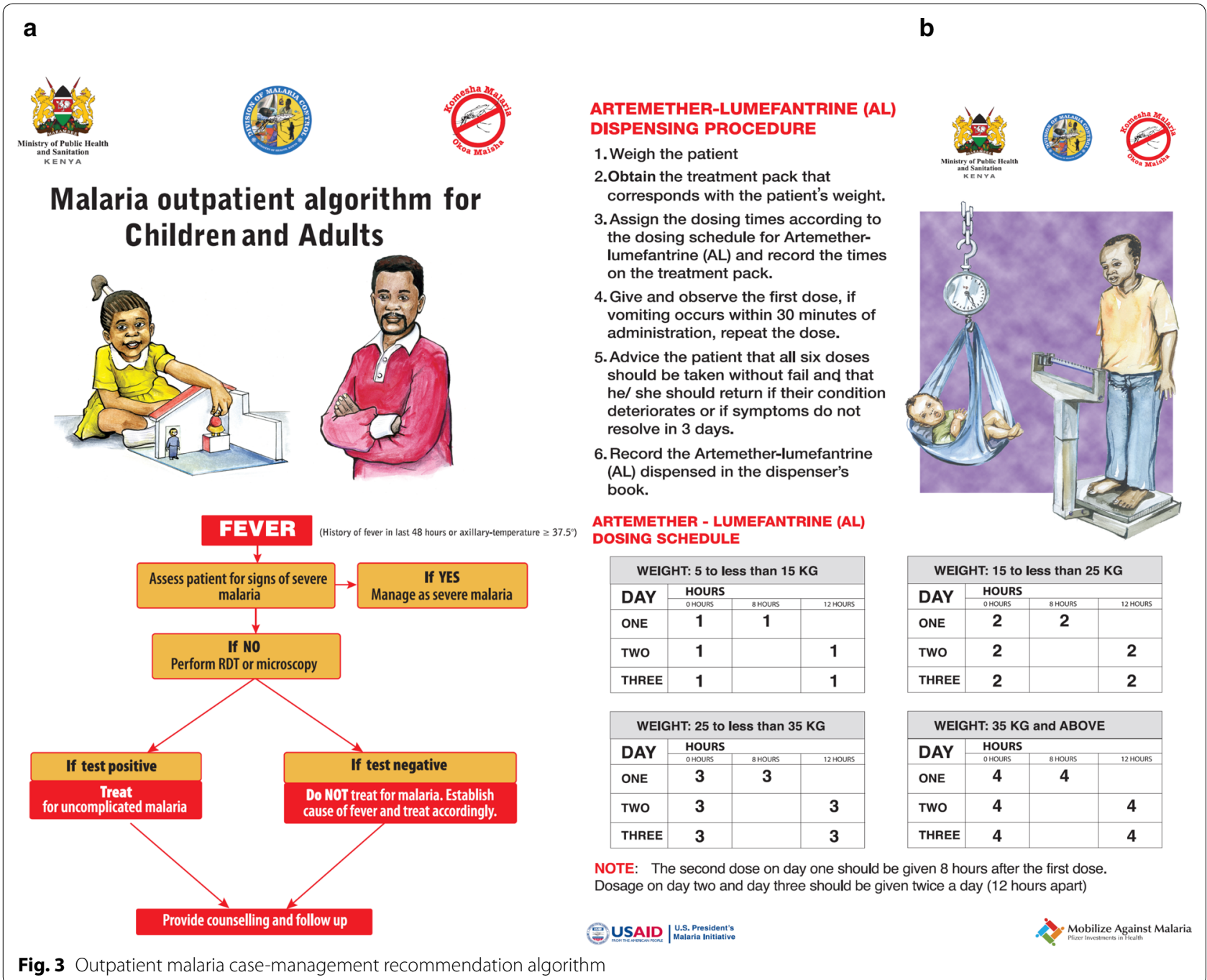

training and support supervision' (OTSS)], electronic data collection and follow-up evaluation, and implementation of the lessons learned. By 2016, two rounds of OTSS were conducted reaching $98 \%$ coverage of the facilities in the region and this might have contributed to the high compliance levels noted in the zone at the last survey (Fig. 2) [47, 48].

\section{Data sources}

The study utilized data from 11 national, biannual, crosssectional, cluster sample health facility surveys undertaken between January 2010 (before the 'test and treat' policy was introduced) and July 2016. For each survey, a proportionate stratified random sample of facilities was drawn from the Ministry of Health $(\mathrm{MoH})$ master list of all public health facilities, taking into consideration administrative boundaries to ensure national representativeness [49]. The number of assessed facilities ranged between 169 and 176 facilities per survey. At each of the surveyed facilities, data collection methods included health facility assessments, interviews with health workers and exit interviews with all eligible outpatients during one survey day when they were ready to leave the facility $[18,21]$. The patients' exit interviews included all non-referred for admission and non-pregnant patients weighing $>5 \mathrm{~kg}$ across all age groups and presenting for an initial visit with fever or history of fever. Information was collected from patient-held cards about malaria tests requested, test results, treatment prescribed, and direct questioning about drug dispensing and counselling practices during the facility visit. At each facility, the availability of AL, RDTs and malaria microscopy was determined for the survey day. Data quality was assured through five days of training of the field workers, double-entry into Microsoft Access database, and data files comparisons 
using a verification program in Microsoft Access and referring to paper-based questionnaires.

Indicators, analytical approaches, and statistical analysis A set of 12 indicators of health workers' compliance with national malaria case-management guidelines was selected (Table 1). Four primary indicators reflected health worker decisions to test febrile patients for malaria, comply respectively with test-positive and test-negative results, and a composite indicator of 'test and treat' compliance among all febrile patients. Eight secondary indicators included compliance with the recommended AL dosing among patients who had AL prescribed with complete dosage prescriptions, and seven AL dispensing and counselling tasks evaluated among patients who had AL prescribed and dispensed to be taken at home (Table 1). Since the lack of commodities precludes measurements of 'test and treat' compliance,

Table 1 Compliance with the outpatient malaria guidelines by epidemiological zones in 2010 and 2016, Kenya

\begin{tabular}{|c|c|c|c|c|c|}
\hline $\begin{array}{l}\text { Indicators of malaria case- } \\
\text { management quality }\end{array}$ & Lake endemic & Coast endemic & Highland epidemic & $\begin{array}{l}\text { Semi-arid, seasonal } \\
\text { transmission }\end{array}$ & Low risk \\
\hline \multicolumn{6}{|c|}{ Primary indicators - 'test and treat' compliance } \\
\hline \multicolumn{6}{|c|}{ Malaria testing of febrile patients } \\
\hline Baseline-2010 & $43.5(177 / 407)$ & $40.0(80 / 200)$ & $41.4(86 / 208)$ & $45.9(112 / 244)$ & $39.6(72 / 182)$ \\
\hline Last survey-2016 & $93.9(216 / 230)$ & $76.3(61 / 80)$ & $70.3(85 / 121)$ & $53.1(77 / 145)$ & $24.5(24 / 98)$ \\
\hline \multicolumn{6}{|c|}{ AL treatment for test positive patients } \\
\hline Baseline & $82.7(86 / 104)$ & $71.4(35 / 49)$ & $73.9(17 / 23)$ & $91.4(64 / 70)$ & $93.6(29 / 31)$ \\
\hline Last survey & $98.6(139 / 141)$ & $100(32 / 32)$ & $96.9(31 / 32)$ & $100(12 / 12)$ & $100(3 / 3)$ \\
\hline \multicolumn{6}{|c|}{ Compliance with test negative results } \\
\hline Baseline & $35.6(26 / 73)$ & $48.4(15 / 31)$ & $33.3(21 / 63)$ & $81.0(34 / 42)$ & $56.1(23 / 41)$ \\
\hline Last survey & $89.3(67 / 75)$ & $96.6(28 / 29)$ & $83.0(44 / 53)$ & $90.8(59 / 65)$ & $100(21 / 21)$ \\
\hline \multicolumn{6}{|c|}{ Composite "test and treat" compliance } \\
\hline Baseline & $27.5(112 / 407)$ & $25.0(50 / 200)$ & $18.3(38 / 208)$ & $40.2(98 / 244)$ & $28.6(52 / 182)$ \\
\hline Last survey & $89.6(206 / 230)$ & $75.0(60 / 80)$ & $62.0(75 / 121)$ & $49.0(71 / 145)$ & $24.5(24 / 98)$ \\
\hline \multicolumn{6}{|c|}{ Secondary indicators-AL dosing, dispensing and counselling compliance } \\
\hline \multicolumn{6}{|c|}{ Correct prescribing of AL dose } \\
\hline Baseline & $92.7(240 / 259)$ & $91.2(83 / 91)$ & $91.3(105 / 115)$ & $86.9(106 / 122)$ & $86.4(51 / 59)$ \\
\hline Last survey & $94.6(139 / 147)$ & $85.3(29 / 34)$ & $97.5(39 / 40)$ & $89.5(17 / 19)$ & $100(3 / 3)$ \\
\hline \multicolumn{6}{|c|}{ Weighing of patients prescribed $A L$} \\
\hline Baseline & $61.9(169 / 273)$ & $48.2(53 / 110)$ & $51.2(62 / 121)$ & $37.2(55 / 148)$ & $33.3(20 / 60)$ \\
\hline Last survey & $83.9(125 / 149)$ & $74.3(26 / 35)$ & $55.0(22 / 40)$ & $52.6(10 / 19)$ & $33.3(1 / 3)$ \\
\hline \multicolumn{6}{|c|}{ First $A L$ dose administered at the facility } \\
\hline Baseline & $41.4(113 / 273)$ & $14.6(16 / 110)$ & $37.2(45 / 121)$ & $16.2(24 / 148)$ & $20.0(12 / 60)$ \\
\hline Last survey & $69.1(103 / 149)$ & $97.1(34 / 35)$ & $27.5(11 / 40)$ & $26.3(5 / 19)$ & $33.3(1 / 3)$ \\
\hline \multicolumn{6}{|l|}{ Explanation of AL dosage } \\
\hline Baseline & $98.2(268 / 273)$ & $97.3(107 / 110)$ & $92.6(112 / 121)$ & $94.6(140 / 148)$ & $91.7(55 / 60)$ \\
\hline Last survey & $98.0(146 / 149)$ & $97.1(34 / 35)$ & $97.5(39 / 40)$ & $89.5(17 / 19)$ & $100(3 / 3)$ \\
\hline \multicolumn{6}{|c|}{ Advised to take the second $\mathrm{AL}$ dose after $8 \mathrm{~h}$} \\
\hline Baseline & $70.3(192 / 273)$ & $90.9(100 / 110)$ & $67.8(82 / 121)$ & $56.1(83 / 148)$ & $66.7(40 / 60)$ \\
\hline Last survey & $91.9(136 / 148)$ & $91.4(32 / 35)$ & $95.0(38 / 40)$ & $89.5(17 / 19)$ & $100(3 / 3)$ \\
\hline \multicolumn{6}{|c|}{ Advised to take drugs after meals } \\
\hline Baseline & $54.6(149 / 273)$ & $72.7(80 / 110)$ & $68.6(83 / 121)$ & $53.4(79 / 148)$ & $53.3(32 / 60)$ \\
\hline Last survey & $76.2(112 / 147)$ & $68.6(24 / 35)$ & $42.5(17 / 40)$ & $84.2(16 / 19)$ & $33.3(1 / 3)$ \\
\hline \multicolumn{6}{|c|}{ Advised what to do in case of vomiting } \\
\hline Baseline & $5.9(16 / 273)$ & $9.1(10 / 110)$ & $1.7(2 / 121)$ & $2.0(3 / 148)$ & $1.7(1 / 60)$ \\
\hline Last survey & $10.1(15 / 149)$ & $17.1(6 / 35)$ & $2.5(1 / 40)$ & $5.3(1 / 19)$ & $0(0 / 3)$ \\
\hline \multicolumn{6}{|c|}{ Advised to complete all AL doses } \\
\hline Baseline & $76.6(209 / 273)$ & $70.9(78 / 110)$ & $81.8(99 / 121)$ & $76.4(113 / 148)$ & $80.0(48 / 60)$ \\
\hline Last survey & $87.2(129 / 148)$ & $85.7(30 / 35)$ & $87.5(35 / 40)$ & $84.2(16 / 19)$ & $100(3 / 3)$ \\
\hline
\end{tabular}


the analysis was restricted to the facilities with available $\mathrm{AL}$ and malaria diagnostics.

For each of the 12 compliance indicators, the primary analytic approach was to estimate temporal trends within each malaria risk zone and compare the trends across the zones over 11 survey rounds from January 2010 to July 2016. For a contextual understanding of these trends, compliance levels for each indicator stratified by malaria risk are calculated for the baseline and the last survey. For each indicator, multilevel mixed-effects logistic regression model was fitted. The clustering of patients within health facilities was accounted for by fitting a random intercept for each health facility [50]. The temporal trends were examined by fitting time as a continuous variable and interaction term between each malaria risk zone and time. Tests for significant interactions were conducted using the Wald test. For the baseline survey, conducted in January 2010, time was set to zero and time in months since the baseline survey was calculated for the consecutive surveys. This was then converted to years by dividing by 12 to estimate the annual change in the performance of each indicator. P-values less than 0.05 were considered statistically significant. The results are presented as time trends (annual odds ratios) with 95\% confidence intervals (CI) and plots of the observed proportion of patients with the outcome versus predicted marginal regression lines. The area under the receiver operating characteristic (ROC) curves was used to evaluate the goodness of fit of the final models. All analyses were conducted using Stata version 14 (StataCorp, College Station, TX, USA).

\section{Results}

The trend analysis across five epidemiological zones included a range of 932 to 2,766 febrile patients aged between 1 month and 98 years, 129 to 1,178 test positive, 321 to 882 test negative, 191 to 1,620 AL prescribed and 184 to 1,570 patients who had AL dispensed at facilities with available 'test and treat' commodities across 11 survey rounds conducted from 2010 to 2016. Over the 11 survey rounds, the number of facilities and health workers who saw febrile patients across the five zones ranged between 93 and 331 (Fig. 1) and 126 and 408, respectively. Table 1 shows the proportions of patients for whom health workers complied with malaria guidelines at the baseline and the last survey, while Table 2, and Figs. 4 and 5 show the compliance trends within each of the five malaria risk zones across all survey rounds.

\section{Malaria 'test and treat' compliance}

The composite compliance with the 'test and treat' policy, measured as a febrile patient tested for malaria and treated according to the test result, was low at the baseline and ranged from 18 to $40 \%$ across the five zones
(Table 1). Within three epidemiological zones, the odds of compliance increased significantly with an annual change of $80 \%$ in the lake endemic $(\mathrm{OR}=1.80$ annually; $95 \% \mathrm{CI}=1.61-2.01), 47 \%$ in the highland epidemic $(\mathrm{OR}=1.47 ; 95 \% \mathrm{CI}=1.32-1.65)$ and $24 \%$ in the coast endemic $(\mathrm{OR}=1.24 ; 95 \% \mathrm{CI}=1.05-1.46)$ zones. The annual trends were significantly higher within the lake endemic compared to the highland epidemic $(p=0.015)$ and coast endemic $(\mathrm{p}<0.001)$ zones. There were no significant changes in the performance trends within the semi-arid seasonal transmission and low risk zones (Table 2 and Fig. 4). At the last survey, the composite 'test and treat' performance was highly variable across the zones and ranged from $25 \%$ in the low risk area to $90 \%$ in the lake endemic zone (Table 1).

The trends in the specific components of the 'test and treat' pathway are specified below. The levels of compliance with malaria testing of febrile patients were similar across the five zones and ranged between 40 and $46 \%$ at the baseline (Table 1). The proportion of patients who were tested significantly increased over time in the lake endemic to $94 \%(\mathrm{OR}=1.71 ; 95 \% \mathrm{CI}=1.51-1.93)$ and highland epidemic areas to $70 \%(\mathrm{OR}=1.32 ; 95 \%$ $\mathrm{CI}=1.18-1.49$ ) (Table 2). The annual increase in testing was significantly higher in the lake endemic compared to the highland epidemic areas $(p=0.003)$. In contrast, there was some evidence of a decline in the proportion of patients tested over time within the low-risk zone to $25 \%$ by $2016(\mathrm{OR}=0.89 ; 95 \% \mathrm{CI}=0.79-1.01)$. No significant changes were observed in the semi-arid seasonal transmission and coast endemic zones (Table 2). In the coast endemic zone, variability in the proportion of tested patients was observed between surveys resulting in no consistent time trend (Table 2 and Fig. 4).

Prescription of AL to confirmed malaria cases ranged between zones from $71 \%$ in the coast endemic area to 94\% in the low risk zone at baseline (Table 1). Despite relatively high baseline levels, AL prescribing for test-positive patients showed significant and similar $(\mathrm{p}=0.638)$ time trends within the lake $(\mathrm{OR}=1.56 ; 95 \% \mathrm{CI}=1.26-$ $1.92)$ and coast endemic $(\mathrm{OR}=1.77 ; 95 \% \mathrm{CI}=1.07-2.94)$ zones and no significant changes within the highland epidemic, semi-arid seasonal transmission, and low risk zones over time (Table 2 and Fig. 4). In the last survey, a range of 97 to $100 \%$ of confirmed malaria cases were prescribed AL across the five zones (Table 1).

Lastly, withholding anti-malarial treatment for patients who tested negative was variable at the baseline and ranged from 33 to $81 \%$ across the five zones. The semiarid seasonal transmission areas had the highest levels of compliance $(81 \%)$ while 33 and $36 \%$ of test-negative patients were not, respectively, prescribed an anti-malarial in the highland and lake endemic zones (Table 1). 


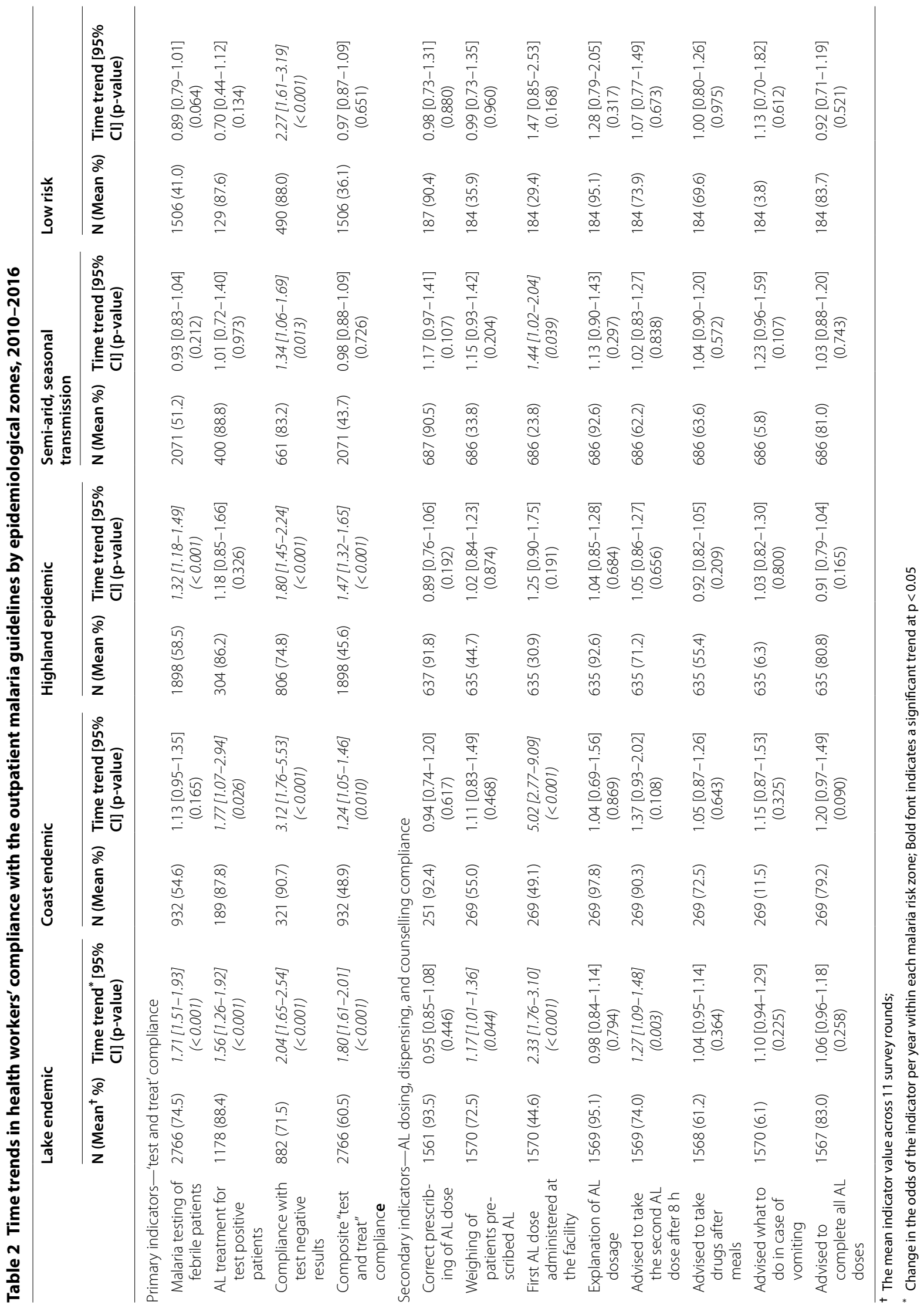




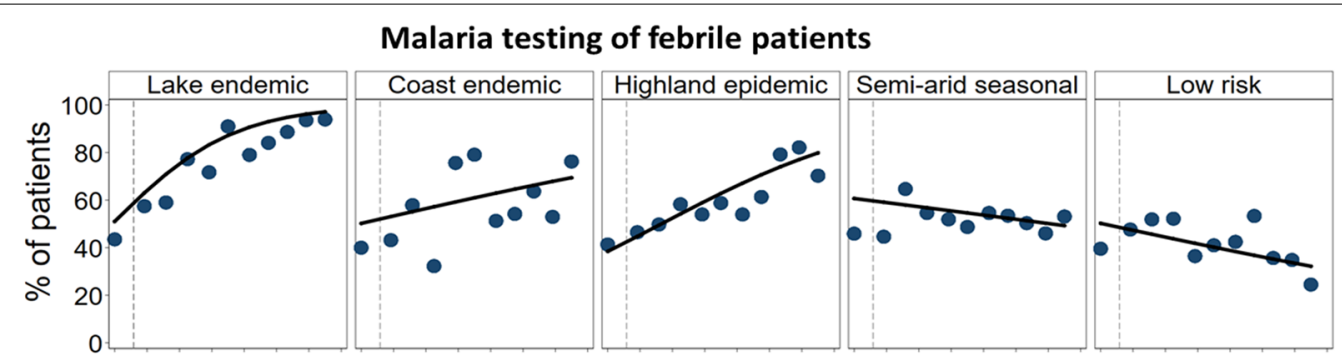

AL treatment for test positive patients

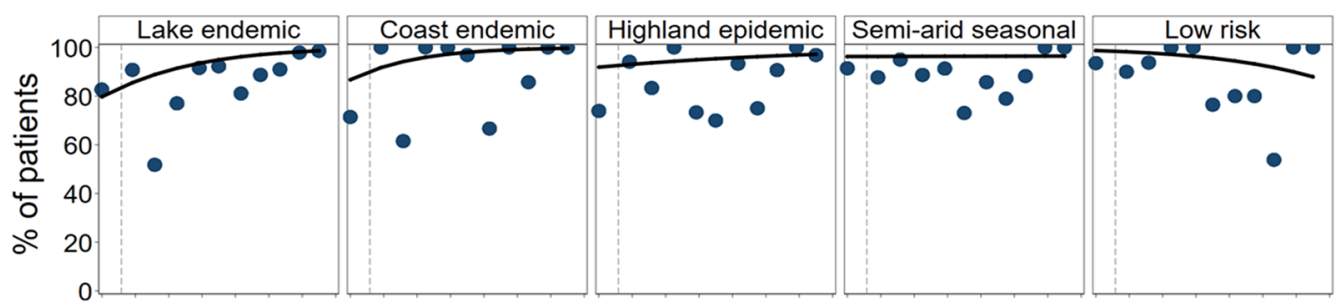

Compliance with test negative results

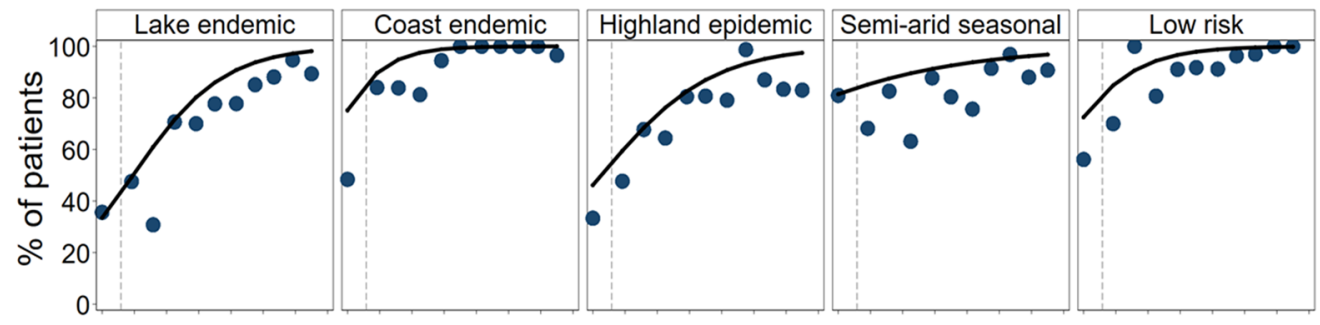

Composite test and treat compliance

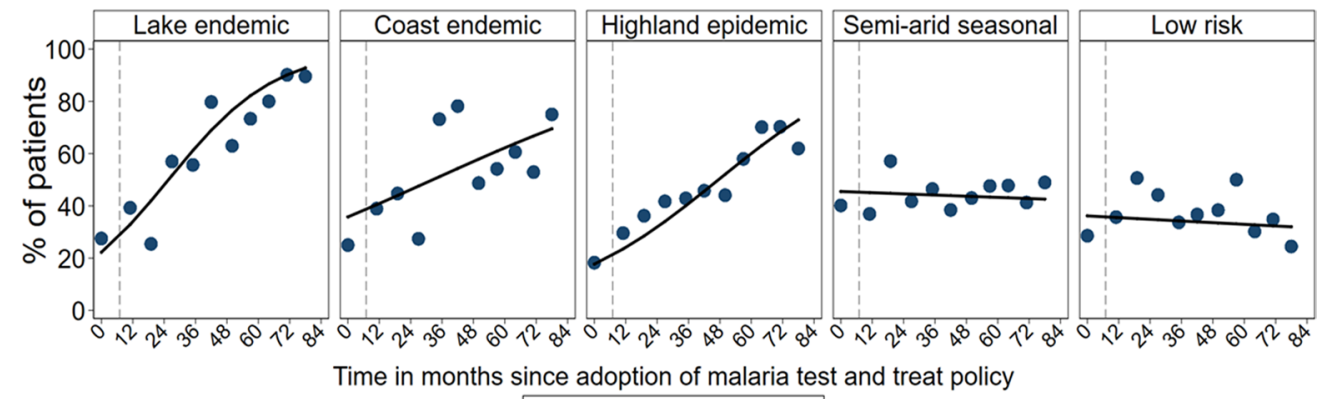

- Actual - Predicted

Fig. 4 Time trends in health workers' compliance with outpatient malaria 'test and treat' policy by malaria epidemiological zones

Across all five malaria risk zones, compliance with test-negative results significantly increased over time with an annual increase in the odds of thrice within the coast endemic $(\mathrm{OR}=3.12 ; 95 \% \mathrm{CI}=1.76-5.53)$, twice in the low risk $(\mathrm{OR}=2.27 ; 95 \% \mathrm{CI}=1.61-3.19)$ and lake endemic $(\mathrm{OR}=2.04 ; 95 \% \mathrm{CI}=1.65-2.54), 80 \%$ in the highland epidemic $(\mathrm{OR}=1.80 ; 95 \% \mathrm{CI}=1.45-2.24)$ and $34 \%$ in the semi-arid seasonal transmission $(\mathrm{OR}=1.34$; $95 \% \mathrm{CI}=1.06-1.69)$ areas. The annual trends were significantly higher within the lake endemic $(p=0.008)$, coast endemic $(\mathrm{p}=0.007)$, low risk $(\mathrm{p}=0.012)$ compared to the semi-arid seasonal transmission areas (Table 2 and Fig. 4). During the last survey, the proportion of test-negative patients who were not prescribed an anti-malarial was high in all zones and ranged from $83 \%$ in the highland epidemic zone to $100 \%$ in the low risk area (Table 1 ).

\section{AL dosing, dispensing, and counselling compliance}

At the baseline, the levels of eight AL dosing, dispensing, and counselling performance tasks differed between 


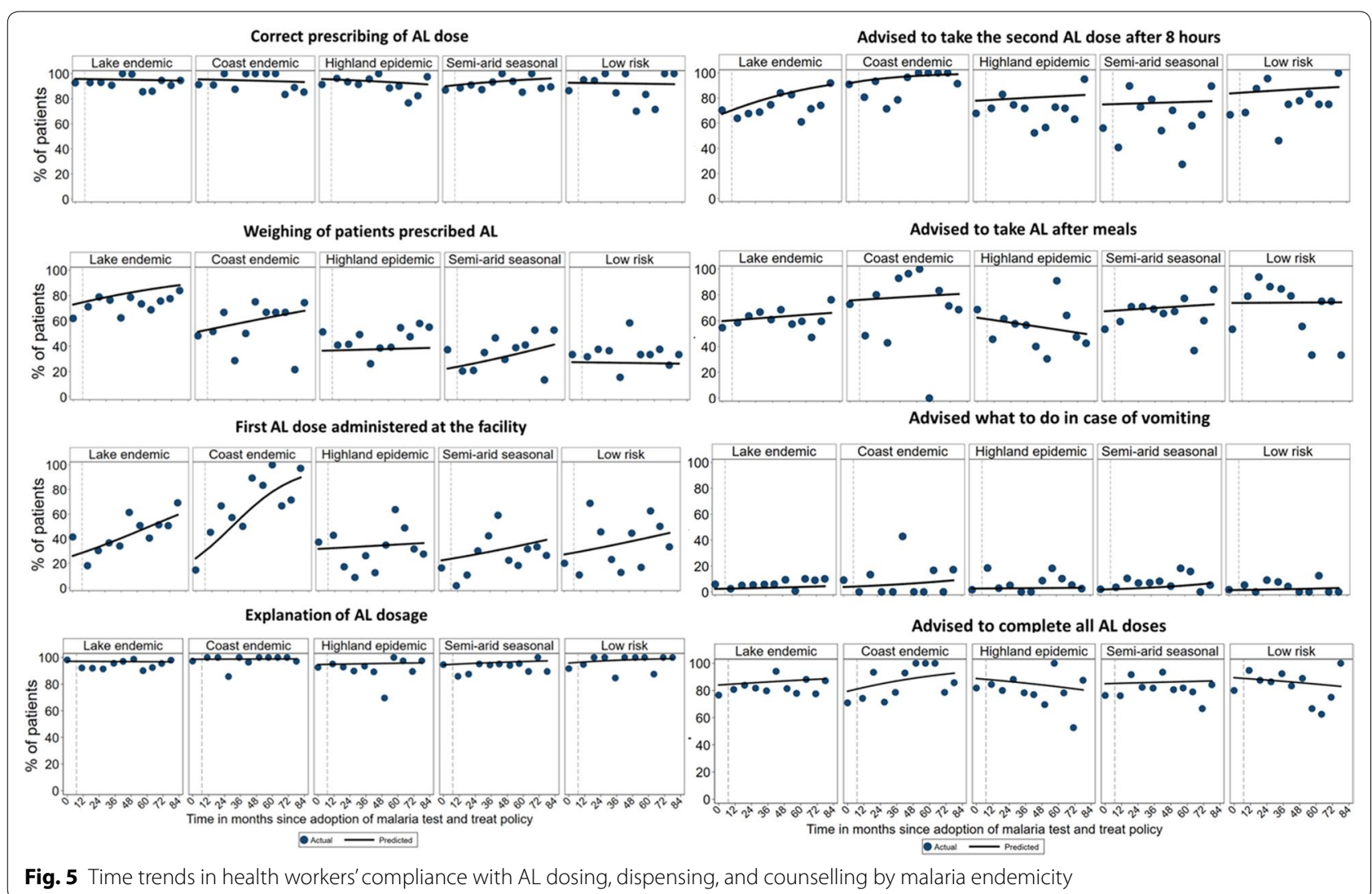

the evaluated tasks (Table 1). Correct prescribing of $\mathrm{AL}$ dose and explaining of AL dose to be taken at home was at high-performance levels and for the respective tasks ranged across five zones from 86 to $93 \%$ and from 92 to $98 \%$. The health workers' performance of the remaining six tasks was much lower at the baseline with the following task range across malaria zones: weighing 33-62\%; administration of the first AL dose $15-41 \%$; and, provision of advice on taking the second AL dose after eight hours $56-91 \%$, to take AL after meals $53-73 \%$, to complete all AL doses $71-82 \%$, and what to do in case of vomiting 2-9\% (Table 1 ).

The proportion of patients who had the first dose of AL administered at the facility significantly increased over time in three malaria zones with the odds increasing five times annually within the coast endemic $(\mathrm{OR}=5.02 ; 95 \%$ $\mathrm{CI}=2.77-9.09)$, twice in the lake endemic $(\mathrm{OR}=2.33$; $95 \% \mathrm{CI}=1.76-3.10)$ and $44 \%$ within the semi-arid seasonal transmission $(\mathrm{OR}=1.44 ; 95 \% \mathrm{CI}=1.02-2.04)$ zones. The annual trends were significantly higher within the coast endemic zone compared to lake endemic $(p=0.014)$ and semi-arid seasonal transmission areas $(\mathrm{p}<0.001)$. In the lake endemic zone, significant annual improvement trends were also observed in the weighing of patients $(\mathrm{OR}=1.17 ; 95 \% \mathrm{CI}=1.01-1.36)$ and in advising patients to take the second AL dose after eight hours $(\mathrm{OR}=1.27 ; 95 \% \mathrm{CI}=1.09-1.48)$. In the highland and low risk areas, none of the eight monitored tasks showed significant changes over time (Table 2 and Fig. 5).

Proportions of patients who received correct AL dosing, explanation of AL dose and provision of advice to take AL after meals, to complete all AL doses, and what to do in case of vomiting showed no significant changes over time in any of the five epidemiological zones (Table 2 and Fig. 5). With the exception of advice on vomiting, which was rarely offered throughout the monitoring period and across all zones (range 0 to $17 \%$ ), the last survey found that all of the seven remaining AL dosing, dispensing and counselling tasks were performed for more than two-thirds of the patients in the lake and coast endemic areas, while in the highland, semi-arid seasonal transmission and low risk areas, the performance in the administration of the first AL dose at the facility was significantly lower and ranged across these three zones from 26 to $33 \%$ (Table 1 ).

\section{Discussion}

The analysis across malaria epidemiological zones revealed important spatial differences in health workers' compliance with outpatient guidelines, which has 
implications for future malaria case-management in Kenya. Overall, major improvement trends in health workers' 'test and treat' practices were found in an area of the highest malaria risk around Lake Victoria where by the end of the monitoring period over $90 \%$ of all febrile patients were both tested and treated according to guidelines. Moreover, it was only in this area that the performance of several drug dispensing and counselling tasks significantly improved. In low malaria risk areas, and particularly in areas of very low risk in central Kenya, no significant changes have been observed in the performance of any of the case-management tasks, except in compliance with the no anti-malarial policy for test-negative, patients which improved in all epidemiological zones.

Malaria testing of all febrile patients is a critical, early step of malaria case-management [35] which if not systematically performed leads to missed malaria diagnosis both in high and low transmission settings [51-54]. Low malaria testing rates of fevers have been commonly reported as one of the weakest components of outpatient malaria case-management despite the testing readiness at health facilities $[10,16,22,26,55,56]$. The 2010 findings showing less than half of febrile patients tested for malaria at facilities with available 'test and treat' commodities concur with these reports. Notable differences in testing trends between high and low malaria risk areas were observed between 2010 and 2016. Major improvements in Kenyan high malaria risk areas reaching over $90 \%$ of tested febrile patients, though imperfect, are encouraging findings. However, they are in stark contrast with low risk areas where no improvement, or even declining trends resulting in only a quarter of febrile patients tested in areas of the lowest risk were observed. Both behaviours have been commonly attributed to health workers' practices considering pretest probability perceptions of malaria [34], as similarly shown for other diseases where local epidemiology of diseases influence health workers' selection of diagnostic tests $[57,58]$. The undertesting in low risk areas does not only compromise case-management but also prospects of ensuring good quality routine data through the District Health Information Software2 (DHIS2) for surveillance of parasitologically confirmed cases as an intervention for malaria elimination to which Kenya is aspiring in these areas [59, 60]. Carefully designed and evaluated interventions changing health workers' testing behaviour in low malaria risk areas should be a case-management priority of malaria control programmes and operational researches.

Health workers' compliance with test-negative results is an important case-management component determining the cost-benefit of the test and treat policy for malaria [61]. Despite the improvement in the trends in this practice across Africa [32], rates of $20-30 \%$ of test-negative outpatients treated for malaria have been estimated with large variability of non-compliant practices between individual studies [62]. With respect to malaria transmission, malaria treatments for test-negative patients have been reported in 57 and $7 \%$ of high and low malaria risk hospital outpatients, respectively, in western Kenya in 2012/2013 [19]. This analysis showed high levels of non-compliant practices in 2010 with subsequent major improvements in all epidemiological zones resulting in nearly all test-negative patients not treated for malaria in low risk areas but also in $90 \%$ of the patients for whom health workers complied with the guidelines in areas of the highest malaria risk around the Lake Victoria in 2016. In these high malaria risk areas, likely due to the highest prevalence of disease and a long history of presumptive treatment practices [45], the behavioural changes were the slowest and, even though they are imperfect, high levels of compliance with test-negative results have been observed five years after the policy change.

Treatment with highly efficacious ACT for confirmed cases is one of the direct measures of case-management effectiveness [6, 7]. In Kenya, the ACT policy recommending AL for uncomplicated malaria was implemented in 2006 [44] and health workers' prescribing preferences for other therapy in the presence of ACT has been common during early years of the policy implementation [63, 64], as is similarly shown in other African countries [6568]. Such practices, though at lower levels, have persisted until 2010 in Kenya and were particularly pronounced in the high-risk lake endemic and coastal areas where the use of parenteral anti-malarials on an outpatient basis was a frequent treatment practice [19, 21]. From 2010 onwards, significant improvements were observed in these areas and during the surveys in 2016 irrational use of injectable anti-malarials has nearly disappeared and AL prescribing for confirmed cases has been standardized across all areas of malaria risk.

Despite modest changes in the overall quality of $\mathrm{AL}$ dispensing and counselling across the zones, the major improvement trends observed in the administration of the first AL dose at the facility in the high-risk lake endemic $(\mathrm{OR}=2.3)$ and coastal areas $(\mathrm{OR}=5.0)$ should not be underestimated. Administration of the first AL dose ensures prompt treatment for malaria and is one of the main factors determining patients' adherence to medicines and treatment effectiveness [69-71]. A series of outpatient evaluations, including interventional studies, has not only reported sub-optimal performance of this task but also resilience to practice change $[10,17$, 22 . Under routine conditions of the policy implementation, major improvements have been seen in high transmission areas where most ACT is prescribed in Kenya, 
despite a potential practice conflict between prompt treatment and recommended $\mathrm{AL}$ dosing after a meal. Alongside improvements in the $\mathrm{AL}$ administration at the facility, declining trends in advising patients to take AL at home after a meal were not observed. Interestingly, in areas of low malaria risk, where anti-malarials are rarely prescribed, only minor improvement trends have been observed and $\mathrm{AL}$ administration in these areas remained at very low levels. The findings imply that in low risk areas high workload may not be a reason for poor dispensing practices for anti-malarials, as commonly reported in the past $[9,17,33,72]$. Finally, across the zones and over the years, most patients were correctly dosed, advised on dosing at home and told to "finish" all doses, however, advice on what do in case of vomiting was rarely provided. Since vomiting is common and non-replacement of doses compromises patients' adherence and treatment outcomes [73], further investigations to understand such practices are required. Accountability for replacement doses at the facilities might be one of the systems factors worth exploring as a reason for the low levels of advising patients on what to do in case of vomiting.

This study has some limitations. Within some zones, there was a possibility of failure to detect significant trends due to small sample sizes for some indicators and the presence of variability in compliance levels across the years. Second, the impact of diagnostic and treatment practices on true malaria cases among the universe of febrile patients could not be established due to lack of gold standard testing which was beyond the scope of this compliance study. Finally, the focus of analyses in this manuscript is compliance trends across five epidemiological zones without adjusting for other factors, the potential correlations between compliance and other interventional and non-interventional factors will be explored separately.

\section{Conclusion}

Trends in health workers' compliance with outpatient malaria case-management guidelines differed across different malaria epidemiological zones between 2010 and 2016 in Kenya. The major improvements in health workers' 'test and treat' practices, including improved performance of drug dispensing and counselling, were observed in areas of the highest malaria risk around Lake Victoria. Conversely, in low risk areas, no significant changes have been seen in the performance of any of the case-management tasks, except in compliance with test-negative results, which indeed increased across all epidemiological zones. By the end of 2016, anti-malarial treatment compliance with test-positive results, and somewhat less to test-negative results, has largely become the standard practice across all zones while major undertesting gaps of febrile patients have been revealed in areas of low risk, calling for interventions to change health workers practices in these areas.

\section{Acknowledgements}

The authors of this report would like to thank the Kenya NMCP for permitting us to re-analyse the national health facility survey data. We are grateful to the Global Fund to Fight AIDS, Tuberculosis and Malaria and U.S. President's Malaria Initiative/USAID for funding the surveys.

\section{Authors' contributions}

All authors contributed to the development of the research question, the analysis and interpretation of the study findings. BA wrote the first draft of the manuscript. All authors read and approved the final manuscript. All authors read and approved the final manuscript.

\section{Funding}

Funding for malaria case-management surveys are provided by the Global Fund to Fight AIDS, Tuberculosis and Malaria and U.S. President's Malaria Initiative/USAID. BA and PMM are supported through the DELTAS Africa Initiative (DEL-15-003). The DELTAS Africa Initiative is an independent funding scheme of the African Academy of Sciences (AAS)'s Alliance for Accelerating Excellence in Science in Africa (AESA) and supported by the New Partnership for Africa's Development Planning and Coordinating Agency (NEPAD Agency) with funding from the Wellcome Trust (107769/Z/10/Z) and the UK government. The views expressed in this publication are those of the author(s) and not necessarily those of AAS, NEPAD Agency, Wellcome Trust or the UK government. RWS is funded as a Wellcome Trust Principal Fellow (\#s 103602 and 212176), that provided additional funding for BA and PMM. BA, PMM, PB, RWS, and DZ acknowledge the support of the Wellcome Trust to the Kenya Major Overseas Programme (\#203077).

\section{Availability of data and materials}

The datasets used and analysed during the current study are available from the corresponding author on reasonable request.

\section{Ethics approval and consent to participate}

Ethical approval for the surveys was provided by the Kenyatta National Hospital/University of Nairobi-Ethics and Research Committee (KNH-ERC/R/108). Informed written consent was obtained for all participating patients and health workers.

\section{Consent for publication}

Not applicable.

\section{Competing interests}

The authors declare that they have no competing interests.

\section{Author details}

${ }^{1}$ KEMRI-Wellcome Trust Research Programme, P.O. Box 43640-00100, Nairobi, Kenya. ${ }^{2}$ WorldWide Antimalarial Resistance Network, Oxford, UK. ${ }^{3}$ Centre for Tropical Medicine and Global Health, University of Oxford, Oxford, UK. ${ }^{4}$ Division of National Malaria Programme, Ministry of Health, Nairobi, Kenya.

Received: 12 May 2020 Accepted: 2 November 2020

Published online: 11 November 2020

\section{References}

1. Snow RW, Sartorius B, Kyalo D, Maina J, Amratia P, Mundia CW, et al. The prevalence of Plasmodium falciparum in sub-Saharan Africa since 1900. Nature. 2017;550:515-8.

2. WHO. World Malaria Report 2019. Geneva: World Health Organization; 2019.

3. WHO. T3: Test Treat. Track. Scaling up diagnostic testing, treatment and surveillance for malaria. Geneva: World Health Organization; 2012.

4. WHO. Guidelines for the treatment of malaria. Geneva: World Health Organization; 2010 
5. Baiden F, Malm K, Bart-Plange C, Hodgson A, Chandramohan D, Webster $J$, et al. Shifting from presumptive to test-based management of malaria-technical basis and implications for malaria control in Ghana. Ghana Med J. 2014;48:112-22.

6. Galactionova K, Tediosi F, de Savigny D, Smith T, Tanner M. Effective coverage and systems effectiveness for malaria case management in sub-Saharan African countries. PLoS ONE. 2015;10:e0127818.

7. Littrell M, Miller JM, Ndhlovu M, Hamainza B, Hawela M, Kamuliwo M, et al. Documenting malaria case management coverage in Zambia: a systems effectiveness approach. Malar J. 2013;12:371.

8. Lubell Y, Reyburn H, Mbakilwa H, Mwangi R, Chonya K, Whitty MJC, et al. The cost-effectiveness of parasitologic diagnosis for malariasuspected patients in an era of combination therapy. Am J Trop Med Hyg. 2007;77:128-32.

9. Steinhardt LC, Chinkhumba J, Wolkon A, Luka M, Luhanga M, Sande J, et al. Quality of malaria case management in Malawi: results from a nationally representative health facility survey. PLoS One. 2014;9:e89050.

10. Abdelgader TM, Ibrahim A, M.Elmardi KA, Githinji S, Zurovac D, Snow RW, et al. Progress towards implementation of ACT malaria case-management in public health facilities in the Republic of Sudan: a cluster-sample survey. BMC Public Health. 2012;12:11.

11. Bruxvoort K, Kalolella A, Nchimbi H, Festo C, Taylor M, Thomson R, et al. Getting antimalarials on target: impact of national roll-out of malaria rapid diagnostic tests on health facility treatment in three regions of Tanzania. Trop Med Int Health. 2013;18:1269-82.

12. Johansson EW, Selling KE, Nsona H, Mappin B, Gething PW, Petzold M, et al. Integrated paediatric fever management and antibiotic over-treatment in Malawi health facilities: data mining a national facility census. Malar J. 2016;15:396.

13. Kankpetinge C, Kweku M, Baiden F, Agboli E, Akapoeh D, Takramah W, et al. Clinicians' adherence to implementation of test, treat and track strategy for malaria control among children under-five years in $\mathrm{Ho}$ Municipality, Volta Region, Ghana. Int J Trop Dis Health. 2016;20:1-11.

14. Mavoko M, llombe G, da Luz R, Kutekemeni A, Van Geertruyden JP, Lutumba P. Malaria policies versus practices, a reality check from Kinshasa, the capital of the Democratic Republic of Congo. BMC Public Health. 2015;15:352.

15. Mokuolu OA, Ntadom GN, Ajumobi OO, Alero RA, Wammanda RD, Adedoyin OT, et al. Status of the use and compliance with malaria rapid diagnostic tests in formal private health facilities in Nigeria. Malar J. 2016;15:4.

16. Mubi M, Kakoko D, Ngasala B, Premji Z, Peterson S, Bjorkman A, et al. Malaria diagnosis and treatment practices following introduction of rapid diagnostic tests in Kibaha District, Coast Region. Tanzania Malar J. 2013;12:293.

17. Namuyinga RJ, Mwandama D, Moyo D, Gumbo A, Troell P, Kobayashi $M$, et al. Health worker adherence to malaria treatment guidelines at outpatient health facilities in southern Malawi following implementation of universal access to diagnostic testing. Malar J. 2017;16:40.

18. Nyandigisi A, Memusi D, Mbithi A, Ang'wa N, Shieshia M, Muturi A, et al. Malaria case-management following change of policy to universal parasitological diagnosis and targeted artemisinin-based combination therapy in Kenya. PLoS ONE. 2011;6:e24781.

19. Onchiri FM, Pavlinac PB, Singa BO, Naulikha JM, Odundo EA, Farquhar $C$, et al. Frequency and correlates of malaria over-treatment in areas of differing malaria transmission: a cross-sectional study in rural Western Kenya. Malar J. 2015;14:97.

20. Salomao CA, Sacarlal J, Chilundo B, Gudo ES. Prescription practices for malaria in Mozambique: poor adherence to the national protocols for malaria treatment in 22 public health facilities. Malar J. 2015;14:483.

21. Zurovac D, Githinji S, Memusi D, Kigen S, Machini B, Muturi A, et al. Major improvements in the quality of malaria case-management under the test and treat policy in Kenya. PLoS One. 2014;9:e92782.

22. Plucinski MM, Ferreira M, Ferreira CM, Burns J, Gaparayi $P$, Joao L, et al. Evaluating malaria case management at public health facilities in two provinces in Angola. Malar J. 2017;16:186.

23. Ameme DK, Afari EA, Nyarko KM, Malm KL, Sackey S, Wurapa F. Direct observation of outpatient management of malaria in a rural Ghanaian district. Pan Afr Med J. 2014;19:367.

24. Masanja IM, Selemani M, Khatib RA, Amuri B, Kuepfer I, Kajungu D, et al. Correct dosing of artemether-lumefantrine for management of uncomplicated malaria in rural Tanzania: do facility and patient characteristics matter? Malar J. 2013;12:446.

25. Bawate C, Callender-Carter ST, Nsajju B, Bwayo D. Factors affecting adherence to national malaria treatment guidelines in management of malaria among public healthcare workers in Kamuli District. Uganda Malar J. 2016;15:112.

26. Bilal JA, Gasim Gl, Abdien MT, Elmardi KA, Malik EM, Adam I. Poor adherence to the malaria management protocol among health workers attending under-five year old febrile children at Omdurman Hospital Sudan. Malar J. 2015;14:34.

27. Bottieau E, Gillet P, de Weggheleire A, Scheirlinck A, Stokx J, Das-DoresMosse C, et al. Treatment practices in patients with suspected malaria in Provincial Hospital of Tete, Mozambique. Trans R Soc Trop Med Hyg. 2013;107:176-82

28. Agandaa A, Kweku S, Agboli M, Takase E, Mohamed T, Wisdom T, et al. Implementation and challenges of test, treat and track (T3) strategy for malaria case management in children under five years in the Bongo District. Ghana Clin Res Trials. 2016;2:235-41.

29. Bastiaens GJH, Schaftenaar E, Ndaro A, Keuter M, Bousema T, Shekalaghe SA. Malaria diagnostic testing and treatment practices in three different Plasmodium falciparum transmission settings in Tanzania: before and after a government policy change. Malar J. 2011;10:76.

30. O'Boyle S, Bruxvoort KJ, Ansah EK, Burchett HED, Chandler CIR, Clarke $\mathrm{SE}$, et al. Patients with positive malaria tests not given artemisinin-based combination therapies: a research synthesis describing under-prescription of antimalarial medicines in Africa. BMC Med. 2020;18:17.

31. Mbonye MK, Burnett SM, Naikoba S, Colebunders R, Wouters K, Weaver $M R$, et al. Malaria care in infants aged under six months in Uganda: an area of unmet needs! PLoS ONE. 2015;10:e0123283.

32. Boyce MR, O'Meara WP. Use of malaria RDTs in various health contexts across sub-Saharan Africa: a systematic review. BMC Public Health. 2017;17:470.

33. Pulford J, Smith I, Mueller I, Siba PM, Hetzel MW. Health worker compliance with a "Test And Treat" malaria case management protocol in Papua New Guinea. PLoS One. 2016;11:e0158780.

34. Graz B, Willcox M, Szeless T, Rougemont A. "Test and treat" or presumptive treatment for malaria in high transmission situations? A reflection on the latest WHO guidelines. Malar J. 2011;10:136.

35. Plucinski MM, Guilavogui T, Camara A, Ndiop M, Cisse M, Painter J, et al. How far are we from reaching universal malaria testing of all fever cases? Am J Trop Med Hyg. 2018;99:670.

36. Macharia PM, Giorgi E, Noor AM, Wago E, Kiptui R, Okiro EA, et al. Spatiotemporal analysis of Plasmodium falciparum prevalence to understand the past and chart the future of malaria control in Kenya. Malar J. 2018;17:340.

37. Ministry of Public Health and Sanitation/Ministry of Medical Services. National Guidelines for Diagnosis, Treatment and Prevention of Malaria in Kenya. Nairobi; 2010.

38. National Malaria Control Programme, Kenya National Bureau of Statistics, ICF International. Kenya Malaria Indicator Survey 2015. Nairobi, 2016.

39. Ministry of Public Health and Sanitation. National Malaria Policy. Nairobi: Division of Malaria Control; 2010.

40. Noor AM, Gething PW, Alegana VA, Patil AP, Hay SI, Muchiri E, et al. The risks of malaria infection in Kenya in 2009. BMC Infect Dis. 2009;9:180.

41. Gething PW, Van Boeckel TP, Smith DL, Guerra CA, Patil AP, Snow RW, et al. Modelling the global constraints of temperature on transmission of Plasmodium falciparum and P. vivax. Parasit Vectors. 2011;4:92.

42. Stevens FR, Gaughan AE, Linard C, Tatem AJ. Disaggregating census data for population mapping using random forests with remotely-sensed and ancillary data. PLoS One. 2015;10:1.

43. Worldpop, Department of Geography and Geosciences, University of Louisville, Department de Geographie Universite de Namur, CIESIN Columbia University. Global High Resolution Population Denominators Project; 2018.

44. Amin AA, Zurovac D, Kangwana BB, Greenfield J, Otieno DN, Akhwale WS, et al. The challenges of changing national malaria drug policy to artemisinin-based combinations in Kenya. Malar J. 2007;6:72.

45. Ministry of Health. National Guidelines for Diagnosis,Treatment and Prevention of Malaria for health workers in Kenya. Division of Malaria Control, Nairobi; 2006. 
46. MalariaCare. Universal Diagnosis and Treatment to Improve Maternal and Child Health, MalariaCare A USAID Partnership. 2015.

47. MalariaCare. Universal Diagnosis and Treatment to Improve Maternal and Child Health: MalariaCare A USAID Partnership. 2016.

48. MalariaCare. Universal Diagnosis and Treatment to Improve Maternal and Child Health: MalariaCare A USAID Partnership. 2017.

49. Ministry of Health. Kenya Health Master Facility List. https://kmhfl.healt h.go.ke/\#/home

50. Hu FB, Goldberg J, Hedeker D, Flay BR, Pentz MA. Comparison of population-averaged and subject-specific approaches for analyzing repeated binary outcomes. Am J Epidemiol. 1998;147:694-703.

51. Chandramohan D, Carneiro I, Kavishwar A, Brugha R, Desai V, Greenwood B. A clinical algorithm for the diagnosis of malaria: results of an evaluation in an area of low endemicity. Trop Med Int Health. 2001;6:505-10.

52. Chandramohan D, Jaffar S, Greenwood B. Use of clinical algorithms for diagnosing malaria. Trop Med Int Health. 2002;7:45-52.

53. Mwangi TW, Ross A, Snow RW, Marsh K. Case definitions of clinical malaria under different transmission conditions in Kilifi District Kenya. J Infect Dis. 2005;191:1932-9.

54. Thwing J, Ba F, Diaby A, Diedhiou Y, Sylla A, Sall G, et al. Assessment of the utility of a symptom-based algorithm for identifying febrile patients for malaria diagnostic testing in Senegal. Malar J. 2017;16:95.

55. Johansson EW, Gething PW, Hildenwall H, Mappin B, Petzold M, Peterson SS, et al. Diagnostic testing of pediatric fevers: meta-analysis of 13 national surveys assessing influences of malaria endemicity and source of care on test uptake for febrile children under five years. PLoS One. 2014;9:e95483.

56. Candrinho B, Plucinski MM, Colborn JM, da Silva M, Mathe G, Dimene M, et al. Quality of malaria services offered in public health facilities in three provinces of Mozambique: a cross-sectional study. Malar J. 2019;18:162.

57. Arroll B, Allan G, Elley CR, Kenealy T, McCormack J, Hudson B, et al. Diagnosis in primary care: probabilistic reasoning. J Prim Health Care. 2012:4:166-73.

58. Heneghan C, Glasziou P, Thompson M, Rose P, Balla J, Lasserson D, et al. Diagnostic strategies used in primary care. BMJ. 2009;338:b946-b.

59. Ministry of Health. Kenya Malaria Strategy 2019-2023. Nairobi: National Malaria Control Programme; 2019.

60. WHO. A framework for malaria elimination. Geneva: World Health Organization; 2017.

61. Lubell Y, Reyburn H, Mbakilwa H, Mwangi R, Chonya S, Whitty CJ, et al. The impact of response to the results of diagnostic tests for malaria: costbenefit analysis. BMJ. 2008;336:202-5.

62. Kabaghe AN, Visser BJ, Spijker R, Phiri KS, Grobusch MP, van Vugt M. Health workers' compliance to rapid diagnostic tests (RDTs) to guide malaria treatment: a systematic review and meta-analysis. Malar J. 2016;15:163.
63. Zurovac D, Njogu J, Akhwale W, Hamer DH, Larson BA, Snow RW. Effects of revised diagnostic recommendations on malaria treatment practices across age groups in Kenya. Trop Med Int Health. 2008;13:784-7.

64. Zurovac D, Njogu J, Akhwale W, Hamer HD, Snow RW. Translation of artemether-lumefantrine treatment policy into paediatric clinical practice: an early experience from Kenya. Trop Med Int Health. 2008;13:99-107.

65. Rowe AK, de Leon GF, Mihigo J, Santelli A, Miller N, Van-Dunem P. Quality of malaria case management at outpatient health facilities in Angola. Malar J. 2009;8:275.

66. Sserwanga A, Harris JC, Kigozi R, Menon M, Bukirwa H, Gasasira A, et al. Improved malaria case management through the implementation of a health facility-based sentinel site surveillance system in Uganda. PLoS ONE. 2011;6:e16316.

67. Webster J, Baiden F, Bawah J, Bruce J, Tivura M, Delmini R, et al. Management of febrile children under five years in hospitals and health centres of rural Ghana. Malar J. 2014;13:261.

68. Zurovac D, Tibenderana JK, Nankabirwa J, Ssekitooleko J, Njogu JN, Rwakimari JB, et al. Malaria case-management under artemether-lumefantrine treatment policy in Uganda. Malar J. 2008;7:181.

69. Beer N, Ali AS, Rotllant G, Abass AK, Omari RS, Al-Mafazy A, et al. Adherence to artesunate-amodiaquine combination therapy for uncomplicated malaria in children in Zanzibar. Tanzania Trop Med Int Health. 2009;14:766-74.

70. Mace KE, Mwandama D, Jafali J, Luka M, Filler SJ, Sande J, et al. Adherence to treatment with artemether-lumefantrine for uncomplicated malaria in rural Malawi. Clin Infect Dis. 2011:53:772-9.

71. Talisuna AO, Oburu A, Githinji S, Malinga J, Amboko B, Bejon P, et al. Efficacy of text-message reminders on paediatric malaria treatment adherence and their post-treatment return to health facilities in Kenya: a randomized controlled trial. Malar J. 2017;16:46.

72. Kaunda-Khangamwa BN, Steinhardt LC, Rowe AK, Gumbo A, Moyo D, $\mathrm{Nsona} \mathrm{H}$, et al. The effect of mobile phone text message reminders on health workers' adherence to case management guidelines for malaria and other diseases in Malawi: lessons from qualitative data from a clusterrandomized trial. Malar J. 2018;17:481.

73. Kachur SP, Khatib RA, Kaizer E, Fox SS, Abdulla SM, Bloland PB. Adherence to antimalarial combination therapy with sulfadoxine-pyrimethamine and artesunate in rural Tanzania. Am J Trop Med Hyg. 2004;71:715-22.

\section{Publisher's Note}

Springer Nature remains neutral with regard to jurisdictional claims in published maps and institutional affiliations.
Ready to submit your research? Choose BMC and benefit from:

- fast, convenient online submission

- thorough peer review by experienced researchers in your field

- rapid publication on acceptance

- support for research data, including large and complex data types

- gold Open Access which fosters wider collaboration and increased citations

- maximum visibility for your research: over $100 \mathrm{M}$ website views per year

At BMC, research is always in progress.

Learn more biomedcentral.com/submissions 